\title{
Perfil enzimático de $\alpha$-amilase, lipase e tripsina do pâncreas e crescimento do fígado, intestino e pâncreas de frangos de corte na fase de 1 a 21 dias de idade $^{1}$
}

\section{George Henrique Kling de Moraes ${ }^{2}$, Ana Claudia Peres Rodrigues ${ }^{3}$, Maria Goreti de Almeida Oliveira $^{2}$, Luiz Fernando Teixeira Albino ${ }^{4}$, Fernanda Álvares da Silva ${ }^{5}$, Rita de Cássia Stampini de Oliveira Lopes ${ }^{2}$}

\footnotetext{
${ }^{1}$ Financiado pela FAPEMIG.

2 Departamento de Bioquímica e Biologia Molecular, UFV, CEP: 36570-000, Viçosa, MG.

${ }^{3}$ Departamento de Bioquímica, UFJF, CEP: 36036-900, Juiz de Fora, MG.

${ }^{4}$ Departamento de Zootecnia, UFV, CEP: 36570-000, Viçosa, MG.

${ }^{5}$ Ministério do Meio Ambiente, CEP: 70.068-900, Brasília, DF.
}

RESUMO - Com o objetivo de avaliar o desenvolvimento de órgãos do aparelho digestório e o perfil enzimático de $\alpha$-amilase, lipase e tripsina, realizou-se um experimento com duração de 21 dias utilizando-se pintos de 1 dia, machos, Avian Farm, criados em baterias aquecidas e alimentados à vontade com água e dieta purificada contendo os L-aminoácidos essenciais, ácido L-glutâmico (fonte de nitrogênio não-específico), minerais e vitaminas. O delineamento experimental foi inteiramente casualizado com quatro repetições de dez aves. No primeiro dia de vida e aos 7, 14 e 21 dias de idade, quatro animais foram sacrificados por deslocamento cervical e o fígado, pâncreas e intestino delgado foram removidos e pesados para determinação das atividades de $\alpha$-amilase, lipase e tripsina. Os pesos absolutos aumentaram com a idade. O peso relativo do pâncreas e dos intestinos reduziu aos 21 dias. As atividades específicas (UI/mg de proteína) das enzimas $\alpha$-amilase e lipase foram maiores no 1 o dia, diminuíram no $7^{\circ}$ dia, alcançando pico máximo no $14^{\circ}$ dia e tornando a reduzir no $21^{\circ}$ dia de idade. A atividade específica (UI/mg de proteína) de tripsina não se alterou com a idade. As atividades relativas da a-amilase, lipase e tripsina (UI/100 g de peso corporal) aumentaram do $1^{\underline{0}}$ ao $14^{\underline{0}}$ dia de idade e reduziram no $21^{\underline{0}}$ de idade. As atividades máximas das enzimas digestivas $\alpha$-amilase e lipase ocorrem no $14^{\circ}$ dia de idade. O perfil enzimático da tripsina, de modo geral, não se altera com a idade, o que pode ser explicado pelo fato de os animais serem criados com dietas purificadas, que não estimulam a produção de enzimas proteolíticas.

Palavras-chave: enzimas digestivas, desenvolvimento enzimático, peso do aparelho digestório

\section{Enzymatic profile of $\alpha$-amylase, lipase and trypsin in the pancreas and the growth of the liver, intestine and pancreas in broiler chicks from one to 21 days of age ${ }^{1}$}

\begin{abstract}
With the objective of assessing the development of organs of the digestive tract and the enzymatic profile $\alpha$-amylase, lipase and trypsin, an experiment lasting 21 days was carried out using one-day-old male Avian Farm broiler chicks, reared in heated batteries and fed ad libitum with water and purified diets containing all L-essential amino acids, glutamic acid (nonspecific nitrogen source), minerals and vitamins. A randomized complete design was used with four replications of ten birds. At one, seven, 14 e 21 days of age, four chicks were sacrificed and the liver, pancreas and intestine were removed and weighed to determine the pancreas a-amylase, lipase e trypsin activities. The absolute weights increased with age. The pancreas and intestine relative weight reduced at 21 days of age. Specific activities (UI/mg protein) of $\alpha$-amylase and lipase were higher on the $1^{\text {st }}$ day, decreased on the $7^{\text {th }}$ day, reaching the maximum peak on the $14^{\text {th }}$ day decreasing again on the $21^{\text {st }}$ day. Trypsin specific activity (UI/mg protein) did not vary with age. The activities per $100 \mathrm{~g}$ of body weight of $\alpha$-amylase, lipase and trypsin (UI/100g body weight) increased from the first to the $14^{\text {th }}$ day of age and showed a reduction on the $21^{\text {st }}$ day. The maximum activities of the digestive enzymes $\alpha$-amylase and lipase occurred on the $14^{\text {th }}$ day of age. The enzymatic profile of trypsin in general did not alter with age, that can be explained by the fact that the animals were raised on purified diets, that did not stimulate proteolytic enzymes.
\end{abstract}

Key Words: digestive enzymes, digestive tract weight, enzymatic development 
em $1 \mathrm{~mL}$ de água destilada e deionizada e centrifugado $\left(4^{\circ} \mathrm{C}\right)$ a $7.000 \times \mathrm{g}$ por 15 minutos.

A atividade da $\alpha$-amilase foi determinada utilizando-se kit específico (In Vitro Diagnostica), que se baseia na hidrólise promovida pela $\alpha$-amilase na molécula do amido, liberando maltose e dextrina, resultando na cor azul, decorrente da complexação do iodo com o amido nãohidrolisado. A atividade de $\alpha$-amilase é inversamente proporcional à intensidade da cor azul e calculada pela comparação a um controle de substrato. A leitura da cor desenvolvida foi feita em $660 \mathrm{~nm}$ e os valores foram expressos em unidades de amilase por $100 \mathrm{~mL}$ da amostra (U\%). A atividade da lipase foi determinada utilizando-se kit específico (In Vitro Diagnostica), baseado em colorimetria, que se fundamenta na reação de hidrólise de um tioéster pela lipase, liberando o tioálcool correspondente e ácido butírico. O tioálcool reage com ácido 5,5 ditio-bis-2nitrobenzóico em meio tamponado, formando um ânion de coloração amarela, cuja intensidade de cor é proporcional à concentração da enzima e apresenta a absorção máxima em 412 nm. Na determinação da atividade de tripsina no pâncreas, procedeu-se inicialmente à ativação do tripsinogênio. Em $1 \mathrm{~mL}$ do sobrenadante, foram adicionados $1 \mathrm{~mL}$ de tampão Tris-HCl, 0,2 M, pH 8,2 contendo $20 \mathrm{mM}$ de $\mathrm{CaCl}_{2}$ e $1,0 \%$ de dimetilformamida e $50 \mu \mathrm{L}$ de tripsina bovina, 4,16 x10-5 M, HCl, 1,0 mM. Essa solução final foi submetida à agitação branda por 2 horas à temperatura ambiente e, imediatamente após, foi determinada a atividade de tripsina pelo método descrito por Erlanger et al. (1961) utilizando-se N-benzoil-D,L-arginina p-nitroanilida (D,L-BApNA) como substrato. As velocidades iniciais foram determinadas pela formação do produto p-nitroanilida, medindo-se o aumento da absorbância a $410 \mathrm{~nm}$ em relação ao tempo e utilizandose o coeficiente de extinção molar de $8.800 \mathrm{M}^{-1} \mathrm{~cm}^{-1}$. Para cada determinação da atividade tríptica no pâncreas, foi feito controle sem enzima. Determinaram-se as diferenças de absorbância entre os testes e os respectivos controles para obtenção da atividade tríptica somente do tripsinogênio ativado. A determinação da concentração de proteína no homogenato do pâncreas foi realizada pelo método descrito por Warburg \& Christian (1941), citado por Whitaker \&
Granum (1980), que utiliza as leituras de absorção em 260 e $280 \mathrm{~nm}$, realizada no intuito de se obter a atividade específica, que é o quociente entre a atividade da enzima em UI e a concentração de proteínas em mg. Os dados foram submetidos à análise de variância utilizando-se o Sistema de Análises Estatísticas e Genéticas - SAEG (UFV, 2000), e as médias foram comparadas pelo teste de Neuman-Keuls a $5 \%$ de probabilidade.

\section{Resultados e Discussão}

Os pesos absolutos de fígado, intestino e pâncreas aumentaram com a idade. O peso relativo máximo dos órgãos foi observado no 14 을 dia, enquanto o peso absoluto aumentou continuamente durante o período experimental (Tabela 2).

Os valores para a atividade específica (UI/mg de proteína) de $\alpha$-amilase e lipase foi maior no $1^{\circ}$ dia e diminui ao 7 ํㅡㅁa, alcançando o pico máximo aos 14 dias e tornando a cair no $21^{\underline{0}}$ dia de idade. Esse comportamento da atividade enzimática coincidiu com o aumento do peso relativo do pâncreas. Monteiro et al. (2006) também observaram o mesmo comportamento para $\alpha$-amilase quando estudaram o efeito de níveis dietéticos de proteína combinados com diversos balanços eletrolíticos. A atividade específica de tripsina não se alterou com a idade, o que pode ser explicado pelo uso de dieta purificada e pela ausência de estímulo de substrato para variação da atividade enzimática.

As atividades (UI/100 g de peso vivo) de $\alpha$-amilase e lipase aumentaram com a idade até o $14^{\circ}$ dia, caindo no 21 음ia (Tabela 3). Esses resultados corroboram outros obtidos por Nitsan et al. (1991), Nir et al. (1993) e Carmo et al. (2003), que observaram que a síntese de enzimas digestivas pancreáticas é deficiente durante o período inicial do crescimento e aumenta até um valor máximo por volta do $10^{0}$ dia após a eclosão, quando a taxa de crescimento relativo é máxima. Esse resultado pode indicar a relação entre esses dois fatores. Para a atividade de tripsina (UI/100 g peso corporal), a maior atividade foi no $21^{\underline{0}}$ e a menor no $1^{\underline{0}}$ dia, enquanto no $7^{\underline{0}}$ e $14^{\underline{0}}$ dias a atividade foi semelhante.

Tabela 2 - Pesos absoluto e relativo de pâncreas, fígado e intestino de frangos de corte

\begin{tabular}{cccccc}
\hline Idade (dias) & Peso & absoluto* $(\mathrm{g})$ & \multicolumn{2}{c}{ Peso relativo (g/100 g peso vivo) } \\
\hline & Fígado & Pâncreas & Intestino & Fígado & Pâncreas \\
01 & $1,24 \mathrm{~d}$ & $0,08 \mathrm{~d}$ & $1,06 \mathrm{~d}$ & $2,48 \mathrm{~d}$ & $0,16 \mathrm{~d}$ \\
07 & $3,18 \mathrm{c}$ & $0,37 \mathrm{c}$ & $3,74 \mathrm{c}$ & $2,12 \mathrm{~d}$ \\
14 & $7,74 \mathrm{~b}$ & $0,81 \mathrm{~b}$ & $7,97 \mathrm{~b}$ & $3,03 \mathrm{c}$ & $0,33 \mathrm{~b}$ \\
21 & $15,73 \mathrm{a}$ & $1,24 \mathrm{a}$ & $10,37 \mathrm{a}$ & $3,89 \mathrm{~b}$ & $0,41 \mathrm{a}$ \\
\hline
\end{tabular}

*Médias seguidas de letras diferentes em cada coluna diferem entre si pelo teste Newman-Keuls $(\mathrm{P}<0,05)$. 
Tabela 3 - Valores médios das atividades de $\alpha$-amilase, lipase e tripsina no pâncreas de frangos de corte do nascimento aos 21 dias de idade

\begin{tabular}{|c|c|c|c|c|c|}
\hline Idade (dias) & Atividade & mg de proteína & UI/mg proteína & UI/g tecido & UI/100 g peso vivo \\
\hline & \multicolumn{5}{|c|}{$\alpha$-amilase (UI) } \\
\hline 01 & $81 \mathrm{a}$ & $8,12 \times 10^{-3} \mathrm{a}$ & $10348 b$ & $15692 \mathrm{a}$ & 1949d \\
\hline 07 & $60 \mathrm{~b}$ & $6,88 \times 10^{-3} \mathrm{a}$ & $9706 \mathrm{~b}$ & $10786 b$ & $3537 b$ \\
\hline 14 & $72 \mathrm{ab}$ & $4,90 \times 10^{-3} \mathrm{~b}$ & $14757 \mathrm{a}$ & $13529 a b$ & $4594 a$ \\
\hline \multirow[t]{2}{*}{21} & $57 b$ & $4,32 \times 10^{-3} \mathrm{~b}$ & $12236 b$ & $11259 b$ & $3116 c$ \\
\hline & \multicolumn{5}{|c|}{ Lipase (UI) } \\
\hline 01 & $25 a$ & $4,27 \times 10^{-3} \mathrm{a}$ & 5749a & $3982 b$ & $594 d$ \\
\hline 07 & $19 b$ & $1,50 \times 10^{-2} \mathrm{~b}$ & $1327 c$ & $3736 \mathrm{~b}$ & $1132 b$ \\
\hline 14 & $23 a$ & $1,10 \times 10^{-2} \mathrm{~b}$ & $2786 b$ & $4761 \mathrm{a}$ & $1718 a$ \\
\hline \multirow[t]{2}{*}{21} & $18^{\mathrm{b}}$ & $1,10 \times 10^{-2} \mathrm{~b}$ & $1697 \mathrm{C}$ & 3492B & $944 \mathrm{C}$ \\
\hline & \multicolumn{5}{|c|}{ Tripsina $\left(\mu \mathrm{Ms}^{-1} \mathrm{~g}^{-1}\right)$} \\
\hline 01 & $1099 \times 10^{-6} \mathrm{C}$ & $0,228 a$ & $490 \times 10^{-5} \mathrm{a}$ & $191 \times 10^{-3} \mathrm{~b}$ & $29 \times 10^{-3} \mathrm{C}$ \\
\hline 07 & $1432 \times 10^{-6} \mathrm{~b}$ & $0,298 a$ & $495 \times 10^{-5} \mathrm{a}$ & $295 \times 10^{-3} \mathrm{a}$ & $94 \times 10^{-3} \mathrm{~b}$ \\
\hline 14 & $1461 \times 10^{-6} \mathrm{~b}$ & $0,278 a$ & $547 \times 10^{-5} \mathrm{a}$ & $328 \times 10^{-3} \mathrm{a}$ & $146 \times 10^{-3} \mathrm{a}$ \\
\hline 21 & $1747 \times 10^{-6} \mathrm{a}$ & $0,283 a$ & $630 \times 10^{-5} \mathrm{a}$ & $346 \times 10^{-3} \mathrm{a}$ & $94 \times 10^{-3} \mathrm{~b}$ \\
\hline
\end{tabular}

* Médias seguidas por letras diferentes em cada coluna diferem entre si $(\mathrm{P}<0,05)$ pelo teste Newman-Keuls.

Esses resultados são semelhantes aos obtidos por Jin etal. (1998) e Carmo et al. (2003). Também Nir etal.(1993), estudando o perfil enzimático de enzimas digestivas no pâncreas de frangos de corte, observaram que a atividade específica de amilase foi maior no dia da eclosão e diminuiu até o $8^{\circ}$ dia de idade, por outro lado, o perfil da atividade específica de lipase é conflitante, pois, neste trabalho, foi maior no primeiro dia, enquanto na pesquisa realizada por Nir et al. (1993) aumentou gradualmente de valores muito baixos na eclosão a um valor 40 vezes maior no 14 을 dia de idade. A atividade de tripsina aumentou gradualmente até atingir um pico no $11^{0}$ dia de idade das aves. Entretanto, Sell et al. (1991) relataram que a atividade específica de lipase pancreática de pintos de 1 dia foi relativamente alta e, posteriormente, apresentou ligeira alteração. Krogdahl \& Sell (1984) observaram que a atividade específica de lipase em pintos diminuiu durante a primeira semana de vida e, posteriormente, aumentou até atingir um platô aos 35 dias de idade. Para a atividade de tripsina, esses autores observaram pequeno aumento até os 14 dias de idade dos animais, que foi seguido de rápida elevação da atividade até o 21ํㅡㅁa. Após esse período, a atividade permaneceu constante até 56 dias de idade. O maior valor de atividade específica para as enzimas $\alpha$-amilase e lipase coincide com o maior peso relativo do pâncreas e sugere uma relação entre a maturação dos órgãos digestivos na presença de substrato e a atividade enzimática. A pouca variação nos valores de atividade da tripsina pode ser explicada pelo uso de dieta purificada e, portanto, pela ausência de substrato.

\section{Conclusões}

O crescimento máximo relativo do pâncreas coincide com a maior atividade relativa da a-amilase e lipase. A atividade da tripsina tendeu a ser constante pelo fato de os animais terem sido alimentados com dietas purificadas e, portanto, não ter havido estímulo para a produção de enzimas proteolíticas.

\section{Literatura Citada}

BAKER, D.H.; HAN, Y. Ideal amino acid profile for chicks during the first three weeks post hatching. Poultry Science, v.73, n.9, p.1441-47, 1994.

CARMO, H.M.; MORAES, G.H.K.; FREITAS, H.T. et al. Development of pancreas lipase and a-amylase of chickens from birth to 21 days of age. In: REUNIÃO ANUAL DA SOCIEDADE BRASILEIRA DE BIOQUÍMICA, 30., 2003, Caxambu. Anais... São Paulo: Sociedade Brasileira de Bioquímica e Biologia Molecular, 2003. p.140.

ERLANGER, B.F.; KOKOWSY, N.; COHEN, W. The preparation and properties of two new chromogenic substrates of trypsin. Archives of Biochemistry and Biophysics, v.95, n.2, p.271-278, 1961.

FEATHERSTON, W.R.; ROGLER, J.C. Methionine-cystine interrelationship in chicks fed diets containing suboptimal levels of methionine. Journal of Nutrition, v.108, n.12, p.1954-1958, 1978.

JIN, S.H.; CORLESS, A.; SELL, J.L. Digestive system development in post-hatch poultry. World's Poultry Science, v.54, n.4, p.335-345, 1998.

KROGDAHL, A.; SELL, L. Development of digestive enzymes and fat digestion. In: WORLD POULTRY CONGRESS, 17., 1984, Helsinki. Proceedings... Helsinki: World Poultry Congress, 1984. p.352-354.

LIMA, A.C.F.; PIZAURO JR., J.M.; MACARI, M. et. al. Efeito do uso de probiótico sobre o desempenho e atividade de enzimas digestivas de frangos de corte. Revista Brasileira de Zootecnia, v.32, n.1, p.200-207, 2003. 
MAIORKA, A.; DAHLKE, F.; MORGULIS, M.S.F.A. Effect of broiler breeder age on pancreas enzymes activity and digestive tract weight of embryos and chicks. Brazilian Journal of Poultry Science, v.6, n.1, p.19-22, 2004.

MONTEIRO, M.P.; MORAES, G.H.K.; FANCHIOTTI, F.E. et al. Alfa-amilase em frangos de corte: efeitos do balanço eletrolítico e do nível protéico da dieta. Revista Brasileira de Zootecnia, v.35, n.3, p.1070-1076, 2006 (supl.)

MORAN JR., E.T. Digestion and absorption of carbohydrates in fowl and the events through perinatal development. Journal Nutrition, v.115, p.665-674, 1985.

NIR, I.; NITSAN, Z.; MAHAGNA, M. Comparative growth and development of the digestive organs and of some enzymes in broiler and egg type chicks after hatching. British Poultry Science, v.34, n.3, p.523-532, 1993.

NITSAN, Z.; DUNNINGTON, E.A.; SIEGEL, P.B. Organ growth and digestive enzyme levels to fifteen days of age in lines of chickens differing in body weight. Poultry Science, v.70, n.10, p.2040-2048, 1991a.

NITSAN, Z.; BEN-AVRAHAM, G.; ZOREF, Z. et al. Growth and development of the digestive organs and some enzymes in broiler chicks after hatching. British Poultry Science, v.32, n.3, p.515-523, 1991b.

NOY, Y.; SKLAN, D. Post hatch development in poultry. Journal Applied Poultry Research, v.6, n.3, p.344-354, 1997.

PENZ JR., A.M. Nutrição na primeira semana. In: SIMPÓSIO INTERNACIONAL SOBRE MANEJO DE PINTOS DE CORTE,
1998, Campinas. Anais... Campinas: Fundação Apinco de Ciência e Tecnologia Avícolas, 1998. p.121-139.

SAKAMURA, N.K.; BIANCHI, M.D.; PIZAURO JR., J.M. et al. Revista Brasileira de Zootecnia, v.33, n.4, p.924-935, 2004.

SELL, J.L.; ANGEL, G.R.; PIQUER, F.J. et al. Developmental patterns of selected characteristics of the gastrointestinal tract of young turkeys. Poultry Science, v.70, n.5, p.1200-1205, 1991.

SHIH, B.L.; HSU, J.C. Development of the activities of pancreatic and caecal enzymes in White Roman goslings. British Poultry Science, v.47, n.1, p.95-102, 2006.

UNIVERSIDADE FEDERAL DE VIÇOSA - UFV. Sistema de análises estatísticas e genéticas - SAEG. Versão 7.1. Viçosa, MG: Universidade Federal de Viçosa, 2000. 150p.

UNI, Z.; NOY, Y.; SKLAN, D. Post hatch development of small intestinal function in the poultry. Poultry Science, v.78, n.2, p.215-222, 1999.

UNI, Z.; GANOT, S.; SKLAN, D. Post hatch development of mucosal function in the broiler small intestine. Poultry Science, v.77, n.1, p.75-78, 1998.

UNI, Z.; NOY, Y.; SKLAN, D. Post hatch changes in morphology and function of the small intestines in heavy- and light-strain chicks. Poultry Science, v.74, n.10, p.1622-1629, 1995.

WHITAKER, J.R.; GRANUM, P.E. An absolute method for protein determination based on difference in absorbance at 235 and 280 nm. Analytical Biochemistry, v.109, p.156-159, 1980.

YOON, S.H.; ROBYT, J.F. Study of inhibition of four alpha amylase by acarbose and its $4^{\mathrm{IV}}$ - $\alpha$-maltododecaosy analogues. Carbohydrate Research, v.338, n.19, p.1969-1980, 2003. 